\title{
SME Growth and Performance: Examining performance dimensions, drivers and Barriers.
}

\author{
Lomatey Isaac Toku*1, Frank Takyi ${ }^{1}$, Smile Dzisi ${ }^{1}$, Joshua Ofori-Amanfo ${ }^{2}$ \\ 1 Koforidua Technical University, Koforidua, Ghana, Faculty of Business and Management Studies \\ 2 University of Ghana Business School, P.O Box LG 78, Legon, Accra \\ ${ }^{*}$ Correspondence: anyemitoku@hotmail.com
}

\begin{abstract}
This study examined SME performance dimensions, including the drivers and barriers to the growth of SMEs. Data for the study was collected from 175 respondents comprising CEOs, MDs and other staffs from SMEs in the Eastern region using the survey method. Data was analyzed using SmartPLS software. The study established that shared responsibility between management and staff, strong leadership and economic opportunities are key factors influencing growth. Entrepreneurial knowledge, experience and educational background are highly predicted when it comes to performance dimension of growth and financial sustainability. However, turbulent marketing conditions; lack of focus and strategic direction resulting from the owner's absence; lack of financing, managerial and technical skills; poor political and economic environment together with the influx of foreign goods on the domestic market were established to adversely affect firm growth. SMEs' growth would, undoubtedly, contribute significantly to improvement in Ghana's GDP, with the potential for job creation for the increasing youth population, hence, appropriate political leadership is required to drive the agenda of SME growth. It is therefore recommended that responsible state agencies such as Ministry of Trade and Industry, NBSSI, in collaboration with financial institutions design and advance soft financial loans and/or assistance to identified distressed SMEs through their registered associations. Besides, government should rope SMEs in the implementation of its One District One Factory policy to attract the necessary state support.

Keywords: Entrepreneur, Growth, Sustainability, SMEs,

Citation: Lomatey Isaac Toku, Frank Takyi, Smile Dzisi, and Joshua Ofori-Amanfo. SMEs growth and performance: performance dimensions, drivers and Barriers, 2020; 5(2): 36-47.
\end{abstract}

Received: March 8, 2019

Accepted: March 31, 2020 


\subsection{Introduction}

Small and Medium Sized Enterprises (SMEs) are known to dominate all economies representing over $90 \%$ of firms in every nation across the globe. In view of their dominance, SMEs play a critical role in economic development. SMEs generally are essential for the existence of large firms, acting as major sources of supply, creativity and innovation. SMEs are perceived to be sources of entrepreneurship, innovation, change agents and major employers (Covin and Miller, 2013). Thus, SMEs make substantial contributions to national output and growth, exports and employment creation resulting in improved Gross Domestic Product (GDP) for a country. The contribution of SMEs to economies is widely acknowledged by both academics and policymakers (Peschken, 2016). Many developing economies are confronted with challenges such as low output from industry, high graduate unemployment, poor resource utilisation, influx of foreign goods unto the local domestic market leading to increased competition among others. The economy of Ghana presently reflects these economic development challenges. These challenges, to a large extent affect the ability of the small firm to grow and remain competitive. SMEs operating in such business environment must have an appropriate strategy in order to survive. As critical as they seem, the sustainability and growth of SMEs is paramount for economic development. SMEs represent an engine of economic growth. The Ghanaian economy requires a vibrant SMEs sector to add value to our natural resource produce such as Gold, Cocoa, Timber and farm products.

Unfortunately, only a handful of SMEs are generally able to expand and develop beyond the micro or informal level (Olomi, 2002). The need for the growth of SMEs continuous to gain considerable attention among academics and policy makers. The recognition that SMEs are important facet of any economic development, has generated a policy debate on how to engender SME growth (Isaga et al., 2015; Abor and Quartey, 2010). Subsequently, this study is intended to explore the key performance dimensions that promote SME growth and sustainability. By this study, we expect to generate insights into the critical determinants of growth for SMEs operating in developing economies such as Ghana. Even though the literature is replete with studies on SMEs operations in Ghana, the issue of growth and sustainability has not been sufficiently explored by researchers. As a result, there is inadequate understanding of how Ghanaian SMEs can grow sustainably within the current business environment and the barriers that may constrain growth effort.

\subsection{Literature Review}

Small and Medium-sized Enterprises (SME) represent an important source of growth for every nation. A vibrant SME base will have significant positive impact on any economy. The SME sector is considered to be the main contributor to both developed and developing countries' economic growth (Lussier and Halabi, 2010). The economic importance of SMEs is widely recognized in both developed and developing countries as it is assumed that they offer significant economic benefits in terms of job creation and income generation (Kang and Heshmati, 2008). Particularly in developing countries, SMEs play a critical role by creating employment opportunities for their large base of unskilled labour (Phillips and Bhatia-Panthaki, 2007; Harson and Shaw, 2001). In Africa, SMEs constitute 
more than 90 per cent of businesses, contributing 50 per cent on the average to employment and GDPs (Akinboade, 2015). Given the importance of SMEs to economic development, their growth and longevity is expected to gain stakeholder attention. Subsequently, the knowledge of SMEs' growth and the understanding of the drivers of growth have gained recognition among both academics and SME owner-managers.

In practice however, the concern is shared that many SMEs have failed in achieving business growth hence, unable to contribute as expected to economic development (Banerjee, 2014). Therefore, there is a compelling need to accelerate the growth of small and medium-sized enterprises and boost their competitiveness to gain more benefit. To be able to develop a robust SMEs sector relevant to economic development, it is imperative that we understand their growth in relation to the associated performance dimensions, as well as the drivers of their performance and barriers of growth.

There exists a large body of literature on SME growth (Bilal et al., 2016; Gill and Biger, 2012; Federico et al., 2012; Forsman, 2008). A great deal of research effort appears to be devoted to identifying the reasons that underlie the variance in growth rates among SMEs. Key studies on SMEs growth however have predominantly focused on North America and Europe with limited research on Africa (Federico et al., 2012). The few Studies focusing on African SMEs (Akinboade, 2015; Adekunle, 2011; Schiebold, 2011; Okurut, 2008; Odd-Helge et al., 2006) have largely done so in the context of assessing the determinants of SMEs' success. Forsman (2008) observes that increasingly, research interest has been tilted towards understanding the impact of the owner-manager's knowledge, skills, capabilities and characteristics on business success.

Firm growth and performance is said to be a complex and multidimensional phenomenon, with variations and differential effect at various levels (Bilal et al., 2016; Davidsson et al., 2002). Growing global rivalry means SMEs are facing a daunting challenge of increasing and maintaining their businesses. Consequently, a coherent and widely accepted theory of firm growth is missing as various theoretical viewpoints are combined to provide an explanation for the growth of firms (Federico et al., 2012). Entrepreneurial motivation has been found to affect SME growth and performance. Entrepreneurs around the world have varied motivations for starting a new business. By extension, the motivations to start a business differ from country to country. Although entrepreneurs in developing countries tend to be driven by income needs, the literature indicates that their counterparts from developed countries are also driven by higher-order needs, including self-realization and self-esteem (Isaga et al., 2015; Benzing et al., 2009; Benzing and Chu, 2009). Further, the entrepreneur's knowledge do influence firm performance to some extent (Omerzel and Antoncic, 2008). This implies that the entrepreneur's knowledge of the internal and external markets, consumer expectations relating to the industry, and knowledge of long-term credit schemes are important for the firm's success and growth.

Knowledge from entrepreneurial experience relating to information, knowledge and abilities, enables the entrepreneur to have good control over operational challenges. Experience provides the entrepreneur with better technical and managerial skills, broader business networks and access to specific, tacit knowledge of markets and the 
needs of customers (Federico et al., 2012). Related to the entrepreneur's knowledge is his / her educational background. Robson and Obeng (2008) surveyed 500 entrepreneurs from six Ghana regions and found that the entrepreneur's education was tied to business success. Thus, entrepreneurs with higher educational background have higher chances of success than those with lower educational levels. Okurut (2008) shares this view with the claim that the level of education of entrepreneurs significantly influences efficiency in small business operations.

A good financial base may support the entrepreneur to pursue growth strategies. Funding for start-ups largely comes from the entrepreneurs' own savings or borrowing from relatives and friends. Entrepreneurs very often, lack sufficient financial resources needed to accelerate growth. The availability of financial support may help budding entrepreneurs to overcome the initial financial challenges that hinder growth. Consequently, Federico et al., (2012) argue that a positive relationship may exist between availability of funds and SME growth.

Isaga et al., (2015) reviewed Tanzania's literature on firm growth to find that most researchers consider firm performance to be significantly affected by external factors and firm characteristics. The assumption is that there are variables that aim to impede or encourage firm growth in the broader market climate. In a literature review, Gill and Biger (2012) summarized that small business growth is adversely affected by lack of financing, lack of management skills, market barriers and regulatory problems. SME development may be the outcome of entrepreneurial strategic decisions or external environment structural features. Morrison et al. (2003) argues that the owner-manager's ability to balance goals and business skills with the incentives from the world is a measurable aspect of a pro-growth small firm.

It has been frequently argued that starting a business comes with great risks. The International Labour Organisation (2005) estimates that the probability of small firms crossing the five-year mark is very low. Thus, rather than growing, these firms tend to die with the failure rate being relatively higher in developing countries (Akinboade, 2015). The survival estimates from the literature suggests that about 24 per cent of business failures happens within year one and two whereas 52 per cent of failures occur within four years (Timmons, 1994).

Due the significant contributions of SMEs to economic development, their growth and performance is a preoccupation of governments and researchers in both the developing and developed worlds. The knowledge of how to grow and sustain the operations of small businesses is fundamental to improving the business survival rate. Insights into the process of business growth, the determinants and drivers will not only promote the development of existing SMEs but will also contribute to enhancing business survival and longevity of start-ups for Ghanaian businesses. SMEs' growth rate could equally be improved if we clearly understand the barriers to their growth in Ghana. Although some business growth factors were established in the literature, due to regional differences, they may not have the same effect on small business growth in each country (Yang and Xu, 2006). To this end, this paper attempts to empirically answer these research questions: 1: What is growth in SMEs 2; What are the essential firm performance dimensions of growth and sustainability in SMEs? 3: What are the drivers/indicators of growth and sustainable business operations in SMEs? And4: What are the hindrances to growth and sustainable business 
operations among SMEs? Accordingly, this research knowledge will contribute to creating a sustainable SME base supporting economic development.

\subsection{Methodology}

An explanatory research approach was adopted for the study. The choice of the explanatory research approach was to enable the causal relationships among SME growth, drivers of growth, indicators of growth and hindrances to growth to be tested. A survey was used to gather the relevant data. Regarding the fact that the cause and effect relationship is invariably conducted in non-contrived settings; the study setting of this research is classified into the field study. The unit of analysis is the organization; manufacturing and service firms in the Eastern Region of Ghana. Moreover, since the data are gathered once, this study can be classified as a cross-sectional study.

The operationalized constructs were assessed using a questionnaire administered. The questionnaire was designed and composed of three sections. The first and second part shows the bio-data and some control variables that affect SMEs. The third part indicates measurement items for firm performance dimensions of growth, hindrance to growth and growth indicators. A five-point Likert scale with end points of "strongly disagree" and "strongly agree" was used to measure all the items. This allowed executives to rank their agreement to a statement relative to positive and negative endpoints of a five-point Likert scale. The survey was distributed and retrieved through both mailing and face to face interaction. The initial mailing comprised an individual cover letter explaining the purpose of the study and a survey questionnaire were sent to all members in the selected sample. Chief Executive Officers (CEOs) and Managing Directors were targeted because they are most familiar with their company's performance outcomes. 175 out of the 365questionnaires administered to respondents from manufacturing and service companies spanning from small to medium sized enterprises were retrieved, giving a $48 \%$ response rate.

\subsection{Results and Discussions}

\subsection{Demographic}

The majority of the SMEs participating in the study were in the service industry because they accounted for over $90 \%$ of the responses. In this context, the SMEs selected for the study were more of service organisations. $47.5 \%$ of the SMEs had a turnover less than GHC50,000. Firms with less than GHC100,000 accounted for 85.3\% of participation. SMEs which have been in existence between 1-10 years constituted $0.2 \%$ which suggests that not many of these SME's are old enough to gain more experience in their venture. This supports the International Labour Organisation's (2005) assertion that the probability of small firms crossing the five-year mark is very low. On the whole the SMEs studied were more skewed to small enterprises compared to medium sized and they were not mature enough. The characteristics of the SMEs studied are presented in Table 1. 
Table 1. Characteristics of SMEs

\begin{tabular}{|l|l|l|}
\hline Sector or Industry & Annual turnover & Years of Existence \\
\hline \multirow{3}{*}{ Manufacturing $(5.2 \%)$} & Less than 50,000 (47.5\%) & $1-10$ years $(70.2 \%)$ \\
\cline { 3 - 3 } & \multirow{2}{*}{$50,000-100,000(37.8 \%)$} & $11-15$ years $(12.4 \%)$ \\
\cline { 3 - 3 } & & $16-20$ years $(8.6 \%)$ \\
\hline Service $(94.8 \%)$ & Above 100,000(14.7\%) & $21-25$ years $(4 \%)$ \\
\cline { 3 - 3 } & & Above 25years $(4.8 \%)$ \\
\hline
\end{tabular}

\subsection{V alidity and Reliability Analysis}

We analyzed our data using SmartPLS software. We chose PLS because of its usefulness in explanatory theorybuilding research and its ability to simultaneously evaluate the measurement and structural models. We tested our model for convergent and discriminant validity and reliability, and performed tests for common methods bias; the tests are shown in Table 2. Our model met or exceeded the accepted thresholds (AVE=0.5, $\mathrm{CR}=0.7$, CA 0.70) (Hair et al 2012) except for PFDG (0.338) and PROG (0.452). However, since PFDG (0.338) and PROG (0.452) has pass both CR and CA test, the construct can be considered as reliable and valid. Convergent validity was demonstrated because all indicators loaded significantly on their respective latent constructs.

Table 2: Validity and Reliability Test

\begin{tabular}{|l|r|r|r|r|r|r|r|r|r|r|r|r|r|r|r|r|}
\hline & \multicolumn{1}{l|}{ CA } & \multicolumn{1}{l|}{ CR } & AVE & EDUB & ENKN & ENMG & HBFB & HEEC & HFCC & HING & IFGG & IGGG & IPGG & PFDG & PROG & STRC \\
\hline EDUB & 0.853 & 0.889 & 0.573 & $\mathbf{0 . 7 5 7}$ & & & & & & & & & & & & \\
\hline ENKN & 0.871 & 0.903 & 0.552 & 0.538 & $\mathbf{0 . 7 4 3}$ & & & & & & & & & & & \\
\hline ENMG & 0.73 & 0.809 & 0.383 & 0.587 & 0.497 & $\mathbf{0 . 6 1 9}$ & & & & & & & & & & \\
\hline HBFB & 0.799 & 0.86 & 0.553 & 0.308 & 0.334 & 0.426 & $\mathbf{0 . 7 4}$ & & & & & & & & & \\
\hline HEEC & 0.865 & 0.9 & 0.604 & 0.439 & 0.375 & 0.469 & 0.659 & $\mathbf{0 . 9 2 4}$ & & & & & & & & \\
\hline HFCC & 0.858 & 0.898 & 0.609 & 0.384 & 0.535 & 0.403 & 0.662 & 0.792 & $\mathbf{0 . 9 3}$ & & & & & & & \\
\hline HING & 0.925 & 0.936 & 0.476 & 0.427 & 0.473 & 0.481 & 0.828 & 0.777 & 0.78 & $\mathbf{0 . 7 8 3}$ & & & & & & \\
\hline IFGG & 0.952 & 0.962 & 0.807 & 0.486 & 0.135 & 0.413 & 0.245 & 0.271 & 0.417 & 0.356 & $\mathbf{0 . 9 3 9}$ & & & & & \\
\hline IGGG & 0.915 & 0.93 & 0.536 & 0.529 & 0.173 & 0.475 & 0.294 & 0.355 & 0.453 & 0.419 & 0.73 & $\mathbf{0 . 9}$ & & & & \\
\hline IPGG & 0.816 & 0.867 & 0.521 & 0.456 & 0.177 & 0.442 & 0.28 & 0.387 & 0.379 & 0.396 & 0.597 & 0.72 & $\mathbf{0 . 8 4}$ & & & \\
\hline PFDG & 0.917 & 0.927 & 0.338 & 0.807 & 0.844 & 0.791 & 0.475 & 0.567 & 0.599 & 0.617 & 0.46 & 0.508 & 0.442 & $\mathbf{0 . 8 6 7}$ & & \\
\hline PROG & 0.886 & 0.907 & 0.452 & 0.602 & 0.717 & 0.703 & 0.626 & 0.674 & 0.786 & 0.69 & 0.465 & 0.509 & 0.433 & 0.58 & $\mathbf{0 . 8 2}$ & \\
\hline STRC & 0.818 & 0.873 & 0.578 & 0.552 & 0.602 & 0.593 & 0.517 & 0.611 & 0.619 & 0.655 & 0.572 & 0.587 & 0.447 & 0.761 & 0.67 & $\mathbf{0 . 8 2 7}$ \\
\hline
\end{tabular}


To evaluate discriminant validity, two tests were performed. First, the cross-loadings of measurement items on latent constructs were examined. Discriminant validity was demonstrated when all items loaded highly on its intended construct than on any other. Therefore, the model demonstrated high discriminant validity. This is to be expected, since each of the variables represents different forms of the same overall phenomenon. Nevertheless, to test for the existence of multicollinearity variance inflation factor (VIF), scores were generated with the SmartPLS software. In our analysis, a few VIF score exceeded 5.4 (a general rule is that the VIF should not exceed 10); therefore, we conclude that multicollinearity was not an issue in our data (Hair et al 2004).

\subsection{Analysis of Structural Model}

This section builds and explains the model. It shows the relationships between the various constructs, their predictions and results. It also depicts which codes were used to explain the various variables. Primarily, the amount of each construct was calculated based on the arithmetic mean of its variables. The outcome of analysis on the structural model is illustrated in Figure 1. The entire variables that measured firm performance which is the independent variable were observed to be loaded well on the construct. ENKN has $\mathrm{R}^{2}$ of 0.713 , EDUB has $\mathrm{R}^{2}$ of 0.651, ENMG has $\mathrm{R}^{2}$ of 0.625 and STRC has $\mathrm{R}^{2}$ of 0.684 . ENKN which is entrepreneur knowledge and experience predict better than the other variables. This also is in line with (Omerzel and Antoncic, 2008; Federico et al., 2012) who claim that entrepreneurs' knowledge and experience do influence firm performance.

Thirteen variables were used to measure the process of SME growth. All of the variables actually measured the process of growth. Example, PROG4 ( $\left.\mathrm{R}^{2}, 0.847\right)$, PROG8 ( $\left.\mathrm{R}^{2}, 0.793\right)$. However, PROG5 ( $\left.\mathrm{R}^{2}, 0.853\right)$, predict better than the other variables, for instance, PROG13 which is $\left(\mathrm{R}^{2}, 0.763\right)$. The relationship between process of growth and firm performance is positive with $\beta(0.713,28.010)$. This implies that entrepreneurial knowledge, experience, educational background, motivation and strategic choices influence entrepreneurial firm performance. All the variables that measured growth indicators measured positively. However, IFGG $\left(\mathrm{R}^{2} 0.882\right)$ which is financial sustainability predict better than physical growth IPGG $\left(\mathrm{R}^{2}, 0.699\right)$. Therefore, the relationship between IGGG and PFDG is positively significant $(B, 0.882,1.573)$. Thus, physical indicators such as multiple locations of offices and market, product popularity together with financial indicators such as financial sustainability and increase sales revenue, predicts firm performance. The results for hindrance of growth (HING) are; $\mathrm{HBFB}\left(\mathrm{R}^{2}, 0.686\right)$, $\mathrm{HEEC}\left(\mathrm{R}^{2}\right.$, $0.854)$ and HFCC $\left(\mathrm{R}^{2}, 0.864\right)$. HFCC which outlines the lack of focus and strategic direction, absence of owner's involvement, lack of managerial and technical skills, financial challenges, lack of business creativity and nature of the product/service in connection to hindrance, constitute the most challenge. The relationship between hindrances of growth (HING) to firm performance is therefore negative. Thus, for example lack of finance, turbulent market conditions and lack of strategic focus and direction adversely affect firm performance. Gill and Biger (2012) claim that there are factors in the wider business environment that tend to hinder or promote firm growth is also supported.

The final results of our theoretical model testing are shown in Fig. 1. Because of the directional nature of each hypothesis, one-tailed tests was used to assess significance of the hypothesized. The relationship between 
HING and PFDG is negatively significant (17.437), implying that there are hindrance that must be taken care of in SMEs failure with which a company will collapse. The relationship between IGGG and PFDG is also significant positively at (1.573) meaning that, there are both physical and financial indicator/drivers of SME growth. PROG and PFDG is also positive at (28.010) as the process of growth significant affect firm performance. However, because HING is negative, it cannot be a driver/indicator of firm performance. Therefore, PROG and IGGG constitute drivers of growth even though there may be other factors. On the whole the values shown are all reliable. This is because all the underlying constructs are less than 0.95; HTMT (Hair et al 2014). Thus, the model fit well.

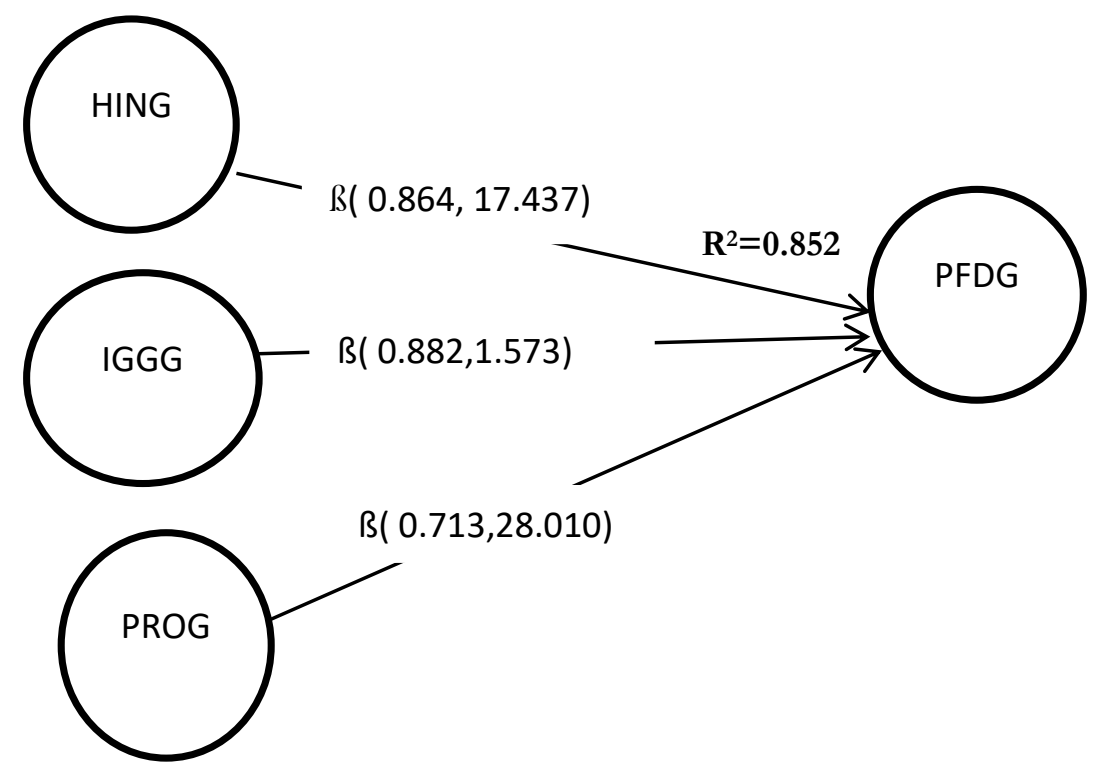

Fig. 1: Independent variable-Hindrance (HING), Indicators of growth (IGGG), Process of growth (PROG) Dependent-Performance (PFDG)

\subsection{Contributions of The Study}

The study contributes to theory by developing understanding to the essential performance dimensions of growth as well as factors that drive SME growth. This understanding represents a source of knowledge on the process of growth among SMEs. Such insights is important for both academics and SME owner-managers who want to know the scientific approach for systematically starting and growing SMEs into large firms. In addition, such theoretical understanding is imperative for Ghana as it intends to pursue a successful industrialisation drive. In effect, the theoretical understandings from this study would contribute to developing a sustainable industrial base for Ghana's economic development. Furthermore, practitioners such as SME owner/managers would be informed on how to grow small firms into big firms. The net effect will be a robust SME base that would support economic development through job creation, poverty alleviation and GDP growth. In terms of policy, the findings from the study would provide policy makers with insights into the key performance dimensions of growth in small firms. These insights 
could affect policy by enabling policy makers to develop appropriate business support strategies for enhancing the development and growth of SMEs.

\subsection{Conclusion}

SMEs growth continues to be a major economic concern, generating research attention. To sum up, all the variables used to measure the various constructs were positively predictive supporting the view that SMEs research are critical in the growth of every economy. It is therefore recommended that responsible state agencies such as the Ministry of Trade and Industry and the National Board for Small Scale Industries (NBSSI) arrange soft financial loans and/or assistance to SMEs in distress through their registered associations. Besides, government should also rope SMEs in the implementation of its One District One Factory policy. This would help to reduce or eliminate some of the challenges that they face, especially that of finance and training assistance.

\subsection{Limitations and Direction for Future Research}

The study has a few limitations that present directions for future research. We considered data from SMEs in the Eastern Region of Ghana only. Hence, we cannot be certain whether these findings will hold in other geographical contexts in both the service and manufacturing sectors. Investigating the existence of probable mediators or moderators in these relationships should be included in the future studies to further share more light on the phenomenon. Again, comparing the implications of this study with outcome of investigation of the same relationships in the service and manufacturing sectors in a different country will enhance the precision of findings. Notwithstanding these limitations, we believe that, to the best of our knowledge, our study is the first to comprehensively consider the relationship betweenfirm dimensions of performance growth, drivers of growth, hindrances to growth and process of growthin SMEs. The findings of this study offer several directions for extending the knowledge-base in the domain of SMEs.

\section{References}

1. Abor, J. and Quartey, P. (2010), Issues in SME development in Ghana and South Africa, International Research Journal of Finance and Economics, No. 39.

2. Adekunle, B. (2011). Determinants of microenterprise performance in Nigeria, International Small Business Journal, 29(4), 360-373.

3. Akinboade, O.A. (2015). Determinants of SMEs growth and performance in Cameroon's central and littoral provinces' manufacturing and retail sectors, African Journal of Economic and Management Studies, 6(2) $183-196$.

4. Banerjee, R. (2014). SMEs financial constraints and growth. BIS Working Papers. Bank for International Settlements, 475, ISSN 1020-0959: ISSN 1682-7678.

5. Benzing, C.M. and Chu, H. (2009). A comparison of motivations of small business owners in Africa, Journal of Small Business and Enterprising Development, 16(1), 60-77. 
6. Benzing, C.M., Chu, H. and Kara, O. (2009). Entrepreneurs in Turkey: a factor analysis of motivations, success factors, and problems, Journal of Small Business Management, 47(1), .58-91.

7. Bilal, A. R., Khan, A. A. and Akoorie, M. E. M. (2016). Constraints to growth: a cross country analysis of Chinese, Indian and Pakistani SMEs, Chinese Management Studies, 10(2), 365-386

8. Covin, J.G. and Miller, D. (2013). International entrepreneurial orientation: conceptual considerations, research themes, measurement issues, and future research directions, Entrepreneurship Theory and Practice, 38(1), 11-44.

9. Davidsson, P., Delmar, F. and Wiklund, J. (2002). Entrepreneurship as growth; growth as entrepreneurship, Strategic Entrepreneurship: Creating a New Integrated Mindset, Blackwell Publishing, Oxford.

10. Federico, J., Rabetino, R. and Kantis, H. (2012). Comparing young SMEs' growth determinants across regions, Journal of Small Business and Enterprise Development, 19(4), 575 - 588.

11. Forsman, H. (2008). Business development success in SMEs: a case study approach, Journal of Small Business and Enterprise Development, 15(3), 606 - 622.

12. Gill, A. and Biger, N. (2012). Barriers to small business growth in Canada, Journal of Small Business and Enterprise Development, 19(4), 656 - 668.

13. Hair, J.F., Hult, G.T.M., Ringle, C.M., Sarstedt, M., 2013. A Primer on Partial Least Squares Structural EquationModeling (PLS-SEM). Sage, Thousand Oaks.

14. Harson, D.W. and Shaw, T.K. (2001). Issues of micro enterprise and agricultural growth: do opportunities exist through forward and backward linkages, Journal of Developmental Entrepreneurship, 6(3), 203-220.

15. International Labour Organisation (2005), "Promoting fair globalization in textiles and clothing in a postMFA environment," report for discussion at the Tripartite Meeting on Promoting Fair Globalization in Textiles and Clothing in a Post-MFA Environment, International Labour Office, Geneva, available at: www.ilo.org/public/english/dialogue/sector/techmeet/tmtcpmfa05/tmtcpmfa-r.pdf (accessed 25th June, 2016).

16. Isaga, N., Masurel, E. and Montfort, K.V. (2015). Owner-manager motives and the growth of SMEs in developing countries, Journal of Entrepreneurship in Emerging Economies, 7(3), 190 - 211.

17. Kang, J.W. and Heshmati, A. (2008). Effect of credit guarantee policy on survival and performance of SMEs in Republic of Korea, Small Business Economics, 31(4), 445-462.

18. Lussier, R.N. and Halabi, C.E. (2010). A three-country comparison of the business success versus failure prediction model, Journal of Small Business Management, 48(3), 360-377.

19. Morrison, A., Breen, J. and Ali, S. (2003). Small business growth: intention, ability and opportunity, Journal of Small Business Management, 41(4), 417-25.

20. Odd-Helge, F., Kolstad, I. and Nygaard, K. (2006). Bribes, taxes and regulations: business constraints for micro enterprises in Tanzania, Chr. Michelsen Institute, CMI. Working paper, p. 2.

21. Okurut, F. (2008). Determinants of microenterprise performance in Uganda, The IUP Journal of Agricultural Economics, 5(1), 77-87.

22. Olomi, D.R. (2002). "Entrepreneurial motivation in developing country context: incidence, antecedents and consequences of growth seeking behaviour among Tanzanian owner-managers", $\mathrm{PhD}$ dissertation, University of Dares Salaam, Dares Salaam. 
23. Omerzel, D.G., and Antoncic, B. (2008). Critical entrepreneur knowledge dimensions for the SME performance. Industrial Management and Data System, 9(108), 1182-1199

24. Peschken, T., Shukla, P., Lennon, J. and Rate, S. (2016). The role of information alignment and entrepreneurial traits on SME internationalization, Management Research Review, 39(2), 196 214.

25. Phillips, C. and Bhatia-Panthaki, S. (2007). Enterprise development in Zambia: reflections on the missing middle, Journal of International Development, 9, 793-804.

26. Robson, P.J. and Obeng, B.A. (2008). The barriers to growth in Ghana, Small Business Economics, 30(4), 385-403.

27. Schiebold, M. (2011). Towards a framework of success determinants for micro-entrepreneurs: the case of Swiss Water Kiosk in Mozambique, Bachelor Thesis, University of St. Gallen

28. Timmons, J.A. (1994), New Venture Creation, Enterprises for the 21st Century, 4th ed., Irwin McGrawHill, Boston

29. Yang, K. and Xu, Y. (2006). Regional differences in the development of Chinese small and medium-sized enterprises, Journal of Small Business and Enterprise Development, 13(2), 174-184. 


\section{Appendix 1}

Codes and their meanings

\begin{tabular}{|l|c|}
\hline Measurement Items & Code \\
\hline Firm Performance dimensions & PFDG \\
\hline Entrepreneur knowledge and experience & ENKN \\
\hline Educational background of the entrepreneur & EDUB \\
\hline Entrepreneur motivation & ENMG \\
\hline Strategic choices & PROG \\
\hline Process of growth & HING \\
\hline Hindrance to growth & HBFB \\
\hline Business financing / Financial base & HEEC \\
\hline External economic conditions & HFCC \\
\hline Firm characteristics & IFGG \\
\hline Indicators of growth & IPGG \\
\hline Financial growth & \\
\hline & \\
Physical growth & PROG4 \\
\hline $\begin{array}{l}\text { Access to funds is an important element in firm } \\
\text { growth }\end{array}$ & PROG8 \\
\hline $\begin{array}{l}\text { Firm growth is a shared responsibility between } \\
\text { management and staff }\end{array}$ & PROG5 \\
\hline & \\
\hline
\end{tabular}

